\title{
Folic acid and the prevention of neural tube defects: exploring the Irish food supply from 2007 to 2014
}

\author{
S.E. Kielthy ${ }^{1}$, K.A. Emerson ${ }^{1}$, G.D. Ussher ${ }^{1}$, F.E. Douglas ${ }^{1}$, O.C. Lyons ${ }^{1,2}$, C.M. Lardner ${ }^{3}$ and $^{2}$ \\ M.A.T. Flynn ${ }^{1,2}$ \\ ${ }^{1}$ Public Health Nutrition, Food Safety Authority of Ireland, Dublin 1, Republic of Ireland, ${ }^{2}$ Northern Ireland Centre for \\ Food and Health, University of Ulster, Coleraine BT52 1SA, UK and ${ }^{3}$ Public Analyst's Laboratory, University College \\ Hospital Galway, Ireland
}

The incidence of Neural Tube Defects (NTDs) in Ireland is increasing ${ }^{(1)}$. To prevent NTDs, sexually active women are recommended to take $400 \mu \mathrm{g}$ folic acid per day (preferably as a folic acid-only supplement) but compliance is low ${ }^{(2)}$. In 2008 , mandatory addition of folic acid to bread in Ireland was put on hold due to high levels of voluntary folic acid food fortification ${ }^{(2)}$. Food supplements placed on the Irish market are required to be notified to the Food Safety Authority of Ireland (FSAI) ${ }^{(3)}$. This study examines food supplements notified since 2007 and folic acid fortified foods marketed in Ireland in 2007 vs. 2014.

Food supplement notifications between 2007 and 2014 (n9483) were assessed to identify folic acid products. Variation in amounts of folic acid provided daily (labelled values) was examined according to year notified, presentation (folic acid-only vs. multi-nutrients) and target population. For a limited range of products, the folic acid content (assessed by liquid chromatography-tandem mass spectrometry) was compared with labelled values. In 2014 a survey examined the labelled amounts of folic acid per portion and per $100 \mathrm{~g}$ of fortified foods marketed in Ireland. This was compared with data from a 2007 survey of the labelled amounts of folic acid per $100 \mathrm{~g}$ of fortified foods.

Between 2007 and 2014, folic acid containing supplements represented an average of $15 \%$ of annual notifications ( $n 1494)$. The median daily folic acid provided $(200 \mu \mathrm{g})$ has remained unchanged. Of these supplements less than $37 \%$ (n557) provide $400 \mu \mathrm{g}$ of folic acid, only $5 \%$ (n68) target non-pregnant women of child-bearing age and just $0.2 \%(n 3)$ of these provide folic acid-only. Significantly higher median daily folic acid amounts are present in folic acid-only supplements compared with multi-nutrient preparations $(400 \mu \mathrm{g} v s .200 \mu \mathrm{g}, \mathrm{p}<0.001)$. Laboratory testing found supplements labelled as providing above $400 \mu \mathrm{g}$ folic acid were more likely to be above acceptable tolerances for labelling ${ }^{(4)}$ when compared with those at or below this daily amount $(\mathrm{p}<0.01)$. The mean variance of analysed folic acid vs. labelled values has significantly decreased (41\% in $2010 v s .5 \%$ in 2014 , p < 0.001$)$. In 2007 vs. 2014, 173 vs. 189 food products were fortified with folic acid. Significant changes have occurred in types of foods fortified and levels of folic acid added, especially for fat spreads. As shown in the table below, significantly lower amounts of folic acid were added in 2014 vs. 2007.

\begin{tabular}{|c|c|c|c|c|}
\hline & $(n)$ & $\begin{array}{l}2007 \\
\text { Median (Range) } \\
(\mu \mathrm{g} / 100 \mathrm{~g})\end{array}$ & $(n)$ & $\begin{array}{l}2014 \\
\text { Median (Range) } \\
(\mu \mathrm{g} / 100 \mathrm{~g})\end{array}$ \\
\hline Cereals & 104 & $170 \cdot 0(19 \cdot 0-571 \cdot 0)$ & 106 & $176 \cdot 0(34 \cdot 0-741 \cdot 0)$ \\
\hline Cereal Bars & 32 & $144 \cdot 0(78 \cdot 0-250 \cdot 0)$ & 52 & $134 \cdot 3(58 \cdot 3-315 \cdot 0)^{*}$ \\
\hline Fat Spreads & 15 & $1000 \cdot 0(100 \cdot 0-1000 \cdot 0)$ & 3 & $500 \cdot 0(500 \cdot 0-500 \cdot 0)$ \\
\hline Milks \& Milky Drinks ${ }^{\dagger}$ & 5 & $63.0(30 \cdot 0-70 \cdot 0)$ & 7 & $70 \cdot 0(70 \cdot 0-266 \cdot 0)^{*}$ \\
\hline Miscellaneous & 17 & $60 \cdot 0(18 \cdot 0-200 \cdot 0)$ & 21 & $40 \cdot 0(17 \cdot 9-2500 \cdot 0)$ \\
\hline
\end{tabular}

Median values significantly different (Mann-Whitney test): ${ }^{*} \mathrm{p}<0.05$

$\dagger$ milk and soya-based drinks

In conclusion, very few folic acid supplements provide the recommended daily amount of $400 \mu \mathrm{g}$ and even fewer target women of child-bearing age as a folic acid-only supplement. Furthermore, folic acid levels in fortified foods have decreased.

1. McDonnel R, Delany V, O'Mahony MT et al. (2015) J Public Health 37, 57-63.

2. Flynn MAT, Anderson WA, Burke SJ et al. (2008) Proc Nutr Soc 67, 381-389.

3. S.I. No. 506 of 2007 European communities (food supplements) regulations 2007 (as amended)

4. European commission. Guidance on setting tolerances for nutrient values declared on a label, 2012. Available from: http://ec.europa.eu/food/food/ labellingnutrition/nutritionlabel/guidance_tolerances_december_2012.pdf 